\title{
Sexually transmitted infections and private physicians in Peru, 2003
}

\author{
Evelyn J. Hsieh, ${ }^{1}$ Magaly M. Blas, ${ }^{1}$ Sayda La Rosa Roca, ${ }^{1}$ \\ and Patricia J. Garcia ${ }^{1}$
}

Suggested citation Hsieh EJ, Blas MM, La Rosa Roca S, Garcia PJ. Sexually transmitted infections and private physicians in Peru, 2003. Rev Panam Salud Publica 2006;20(4):223-9.

\begin{abstract}
Objectives. To analyze demographic and practice characteristics of private physicians in 10 cities of Peru, and to shed light on the role of private practice in the delivery of medical care to patients with sexually transmitted infections (STIs).

Methods. As part of an interventional trial designed to improve physician management of STIs in 10 cities in Peru, detailed information was compiled regarding numbers of physicians in each city. A door-to-door survey was then conducted within each city of all private and public medical offices and institutions. Each physician encountered who had a private practice was asked to answer a questionnaire regarding demographic information, medical education, specialty, type of private and public practices currently engaged in, number of STI cases seen per month, and average earnings per consultation.

Results. Of 2060 physicians working in the 10 cities, 507 reported having a private practice, either exclusively or concurrently with other clinical positions. Almost all the private physicians $(97.4 \%)$ reported managing cases of STIs. Regional differences among private physicians were found in physician density, gender, and place of medical training. In addition, significant variations by gender were seen in rates of specialization, earnings per consultation, and numbers of female patients with STIs seen per month.

Conclusions. Studies of the physician workforce can provide meaningful insights for potential use in addressing public health problems. This study provides valuable information that can help understand the important role of private physicians in managing STIs in Peru.
\end{abstract}

Key words Health manpower, Peru, physicians, private practice, sexually transmitted infections.

In many countries, periodic profiling of physicians helps to assess variations in demographics over time or in

\footnotetext{
Epidemiology, STD/AIDS Unit, School of Public Health, Universidad Peruana Cayetano Heredia, Lima, Peru. Send correspondence and reprint requests to: Patricia J. Garcia, School of Public Health, Universidad Peruana Cayetano Heredia, Av. Honorio Delgado 430 San Martín de Porres, Lima 31, Peru; telephone: (511) 319-0028; fax: (511) 381-9072; e-mail: pattyg@u.washington.edu
}

response to specific changes within the health care system. Understanding these trends provides a natural basis for projections and policy decisions regarding human resources, improving health care access, and structuring medical education (1-12). Previous studies in developing countries have found that private physicians make up a significant part of the health delivery system in both rural and urban areas, and are important sources of ambulatory treatment, which accounts for the largest share of total health care spending (13).

In Peru, some data have been collected by the Ministry of Health (MINSA) and the Peruvian College of Physicians, which grants medical licenses, although the data are not readily available and few analyses have been performed to understand trends 
in physician demographics (14). Up until now, most studies of the Peruvian health workforce have emphasized the public sector, and evaluations of private sector activities have been related with the public sector. These studies have shown that the complexity of the Peruvian health care system creates significant barriers in access to care, and as a result users often rely on nonpublic sources of medical care, including private practitioners. One clear example is the case of sexually transmitted infections (STIs). Treatment of STIs has been shown to be an effective control measure for HIV epidemics. Although most patients with STIs do not seek care from formal health services, studies have shown that private physicians represent an important source for the management of STIs (15-17). In fact, one study reported an estimated ratio of 10:1 for private physician visits versus public health center visits for symptoms of STI such as urethral discharge (18). Another study found that management of STIs by private physicians was severely inadequate (15).

As part of an interventional trial in 10 cities of Peru designed to improve private physician management of STIs, a survey was conducted of all private providers in these cities to assess patterns in demographics, general characteristics, and STI management.

\section{MATERIALS AND METHODS}

\section{Study design}

A survey of private physicians was designed to collect information on physician characteristics, education and training, patient volume, and STI caseload. Ten Andean, coastal, or jungle cities (excluding the capital city of Lima) were chosen for participation in the survey. In each of the cities the goal was to conduct a comprehensive census of all private physicians. No sampling of physicians was performed.

Lima, which is home to one-third of Peru's population and most of the country's health care facilities, was excluded from the study in order to ob- tain information from other provinces without distortion from the disproportionately large capital. The main economic activities in the 10 study cities include agriculture, animal husbandry, hunting and forestry, commerce, and direct services such as repair of vehicles or personal or household items. In addition, mining is a major industry in the Andean region, as is fishing in the coastal cities.

In July and August of 2003, a team of 10 midwives and pharmacists were selected from a pool of respondents to a newspaper advertisement and recruited as local study coordinators. Each individual was selected on the basis of an interview, their curriculum vitae, and prior experience in similar field work. Study coordinators were trained to survey private physicians using a standardized script. In addition, coordinators participated in an 8-h training session on research ethics, how to approach interview subjects, and how to fill out interview forms.

The field work was performed in two phases. Information was first collected regarding the numbers and types of physicians in each city from the regional ministry of health office (DISA), regional Peruvian College of Physicians offices, MINSA hospitals, and social security-based hospitals (EsSalud). For each city all private physicians' offices, polyclinics (small private hospitals), large private hospitals, and other health institutions were mapped, followed by a door-to-door survey of each private physician. Inclusion in the survey required participation in any type of private practice, regardless of concurrent employment in the public sector. Physicians with no private practice were excluded from this study. The rate of nonresponse was less than $1 \%$.

Each private physician encountered was asked to respond face-to-face to a questionnaire prepared for the study, with closed questions regarding demographic information, medical education, specialty, type of private and public practices currently engaged in, number of patients seen per month, number of STI cases seen, number of hours spent working per week, and average fee per consultation. To deter- mine the STIs most frequently seen by these private physicians we asked each physician to list the three most common STIs encountered in their private practice.

\section{Statistical analysis}

All information collected was entered into an Excel database (Microsoft Office 2003, Microsoft, Redmond, Washington, United States). Means or medians were used to analyze central tendency, depending on the distribution of the variable in question. Frequencies were obtained for nominal variables, and Student's $t$ test and two-sample Wilcoxon rank-sum tests were used to perform stratified analyses of certain variables. Statistical analyses were performed with Intercooled STATA software (v. 8.0, STATA Corporation, College Station, Texas, United States).

\section{RESULTS}

\section{Regional differences}

A total of 2060 physicians were identified in the 10 cities. Of these, 507 $(24.6 \%)$ had a private practice either exclusively or concurrently with other clinical positions, and were interviewed. Table 1 shows the distribution of physicians in each city, organized by region, combining findings of the door-to-door census with data from other sources. We calculated the number of physicians per 10000 inhabitants in each city based on numbers extrapolated from a 2005 census of Peru. We found that physician density was higher in the coastal cities than in the Andean and jungle regions (13.7, 8.5 , and 6.7 per 10000 inhabitants, respectively).

A comparison of physicians in private practice only with the total number of private physicians revealed that most private physicians worked concurrently in public practice. Our numbers indicated that $52.5 \%$ of the private physicians had a concomitant practice at a MINSA center; $26.2 \%$ in EsSalud; $6.5 \%$ in police, military, and peni- 
TABLE 1. Distribution of physician population in 10 cities in Peru, 2003

\begin{tabular}{|c|c|c|c|c|c|c|c|}
\hline \multirow[b]{2}{*}{ City } & \multicolumn{5}{|c|}{ Distribution (total number of physicians) ${ }^{a}$} & \multirow[b]{2}{*}{ Total } & \multirow[b]{2}{*}{$\begin{array}{l}\text { Total } \\
\text { number of } \\
\text { private } \\
\text { physicians }\end{array}$} \\
\hline & MINSA & EsSalud & $\begin{array}{l}\text { Police, military, } \\
\text { and penitentiary } \\
\text { health } \\
\text { services }\end{array}$ & $\begin{array}{c}\text { Private } \\
\text { practice } \\
\text { only }\end{array}$ & Other ${ }^{b}$ & & \\
\hline Coast subtotal $($ No. $=4)$ & 436 & 503 & 51 & 67 & 15 & 1072 & 260 \\
\hline Jungle subtotal $($ No. $=2)$ & 194 & 77 & 7 & 13 & 2 & 293 & 84 \\
\hline Andean subtotal $($ No. $=4)$ & 343 & 292 & 18 & 42 & 0 & 695 & 163 \\
\hline Total $($ No. $=10)$ & 973 & 872 & 76 & 122 & 17 & 2060 & 507 \\
\hline
\end{tabular}

tentiary services; $14.7 \%$ as faculty member at a university; and $10.1 \%$ in some other system (e.g., nongovernmental organization, parochial institution, or municipal hospital).

\section{Medical education}

Of the 507 private physicians interviewed, 190 (37.5\%) received undergraduate medical training in Lima, 240 $(47.4 \%)$ in cities other than Lima, and $77(15.2 \%)$ outside of Peru. Of those who trained abroad, the countries where training was most commonly sought were Bolivia $(n=23)$, Argentina ( $n=23)$, Russia and the former Soviet Republics $(n=8)$, Ecuador $(n=8)$, and Mexico $(n=4)$.

When asked about specialty training, 293 individuals $(57.8 \%$ of all the private physicians) reported specialization. The most common specialties were obstetrics and gynecology $(n=$ $120,23.7 \%)$, internal medicine $(n=42$, $8.3 \%)$, general surgery $(n=28,5.5 \%)$, pediatrics $(n=25,4.9 \%)$ and urology ( $n=16,3.2 \%)$. The distribution of physicians with specialty training was similar across all regions studied.

\section{Gender differences}

Table 2 presents selected demographic and professional characteristics of private physicians by gender. Most private physicians were men (77.2\%), and the median age of male physicians

TABLE 2. Selected demographic and professional characteristics of private physicians in 10 cities in Peru by gender, 2003 (No. = 507)

\begin{tabular}{lrrr}
\hline \multicolumn{1}{c}{ Characteristic } & $\begin{array}{c}\text { Male } \\
\text { physicians } \\
\text { (No. = 391) }\end{array}$ & $\begin{array}{c}\text { Female } \\
\text { physicians } \\
\text { (No. = 116) }\end{array}$ & $P$ value \\
\hline Median age in years (range) & $45(25-88)$ & $38(25-58)$ & $<0.01$ \\
With specialty training (\%) & $247(63.2 \%)$ & $46(39.7 \%)$ & $<0.01$ \\
Median hours worked per week (range) & $20(3-168)$ & $20(6-72)$ & 0.54 \\
Fee per consultation (US\$) & & & 0.02 \\
$\quad$ Overall mean & 8.32 & 7.18 & 0.06 \\
$\quad$ Mean nonspecialized & 6.94 & 5.84 & 0.64 \\
$\quad$ Mean specialized & 9.19 & 9.54 & 0.62 \\
Median female patients seen per month (range) & $40(0-600)$ & $40(0-308)$ & 0.08 \\
Median male patients seen per month (range) & $20(0-720)$ & $18(0-200)$ & 0.003 \\
Median female STI cases seen per month (range) & $4(0-150)$ & $5.3(0-80)$ & 0.07 \\
Median male STI cases seen per month (range) & $2(0-65)$ & $2(0-22)$ & \\
\hline
\end{tabular}

(45 years) was significantly older than that of female physicians (38 years, $P<$ 0.01 ). In addition, male private physicians were much more likely to have specialized than female physicians (63.2\% versus $39.7 \%$, respectively, $P<$ $0.01)$. Although male and female physicians both worked a median of 20 hours per week, male physicians earned more per consultation than their female counterparts (mean of US\$ 8.32 per consultation versus US\$ 7.18, $P=0.02$ ). A stratified analysis to evaluate gender differences in earnings between nonspecialized and specialized physicians found a marginally significant difference between male and female nonspecialized physicians (mean of US\$ 6.94 per consultation versus US\$ 5.84, $P=$ 0.06), whereas among specialized physicians the effect of gender was no longer observed (mean of US\$ 9.19 per consultation versus US\$ 9.54, $P=0.62$ ).

Analysis of the geographic distribution of physicians by gender showed that in all regions, male physicians comprised the majority, with the highest proportion of female physicians found in coastal cities and comparatively fewer female physicians in the jungle region ( $24.2 \%$ versus $20.2 \%$, respectively). Both male and female physicians reported seeing a median of 40 female patients per month and approximately half as many male patients per month.

\section{Sexually transmitted infections}

Of 505 physicians who responded to questions regarding STIs, 492 (97.4\%) 
stated that they saw STI cases in their private practice. Overall, physicians reported seeing approximately 7 cases of STI per month out of a median of 60 patient visits per month, representing approximately $12 \%$ of all patient visits. In all regions more female than male patients were found, and the number of STI cases in females was greater than the number in males. Further analysis by physician gender revealed that female physicians diagnosed more cases of female STI per month than male physicians (median: 5.3 cases per month for female physicians versus 4 cases per month for male physicians, $P=0.003$ ), but diagnosed equal numbers of male STI cases (median: 2 cases per month).

Of the 507 physicians surveyed, 435 provided lists of the most common STIs encountered in their private practice. Some physicians reported STIs as syndromes (24\%), but the majority referred to STIs etiologically (73.6\%) despite the fact that laboratory tests were unavailable at the time for several of the reported conditions. The most common syndromes reported were vaginal discharge $(8.6 \%)$, urethral discharge $(6.0 \%)$ and pelvic inflammatory disease (5.2\%), whereas the most common etiologies reported were gonorrhea $(15.7 \%)$, trichomonas (10.9\%), and syphilis (10.2\%).

\section{DISCUSSION}

\section{General features of the medical workforce}

In Peru, health services are grouped in two subsectors: public and private. The public sector consists of MINSAsponsored services, EsSalud, and the health services of the Armed Forces, National Police, and penitentiary services. According to a Pan American Health Organization report from 2002, the public sector represented $51 \%$ of all hospitals in Peru and 69\% of the health centers, and provided $99 \%$ of the health care positions in rural areas and urban settings serving marginalized populations (19).

Based on the 1996 Peruvian census of the health sector (the latest available data), the private sector-which is concentrated in large cities and includes private institutions, doctor's offices, and services offered by other organizations such as nongovernmental organizations-comprised $33.9 \%$ of the workforce. Few studies have attempted to characterize the private sector to evaluate its role in health care delivery. In our study, private practice, whether exclusive or concurrent with public practice, represented $24.6 \%$ of the medical workforce in the cities we surveyed.

The data from our study illustrates the overlap between private and public practice in Peru. The phenomenon of dual public-private practice was also illustrated in a 1995 survey by the Peruvian Escuela Nacional de Salud Publica (ENSAP), which found that only $29 \%$ of all doctors worked in only one position. Almost half of the physicians surveyed worked in two positions, and $22 \%$ held three or more positions. Of note, most of the additional positions held by doctors in the public sector were in the private sector (20). This suggests that public sector salaries are insufficient and that physicians look to other options, such as private practice, as a means of supplementing their income. Information from MINSA and EsSalud establishments in the 10 study cities indicates that the average monthly salary of a physician working for MINSA is approximately US\$828.00, compared to approximately US\$ 1065.00 for those working in EsSalud. In both institutions, physicians work an average of 150 hours per month. Based on the average fee per consultation and number of patients seen per month as reported by private physicians in our study, we estimate that male physicians in private practice earn almost US\$ 500.00 as supplementary income per month, and that the figure for their female counterparts is approximately US\$ 416.00 per month-a substantial contribution to their overall earnings.

\section{Medical education}

Figures from the Peruvian College of Physicians show that the number of licensed medical graduates has almost doubled since 1993 (2 191 physicians in 2003 versus 1293 in 1993). ${ }^{2}$ Likewise, the number of medical schools has increased from 7 in 1967 to 21 in 2005. In fact, 6 out of the 10 cities in our study now have medical schools. In response to the growing number of physicians and medical schools since the mid-1990s, the Ministry of Health has created regulations for the certification of new medical schools.

In $1997,36.9 \%$ of the physicians in Peru practiced a medical specialty, the most common choices being obstetrics and gynecology (13.8\%), pediatrics $(11.2 \%)$, general surgery $(10 \%)$ and internal medicine (9.6\%) (21). In our study $57.8 \%$ of the private physicians surveyed were specialists, and the distribution of medical specialties was similar to that found in the 1997 study. This substantial proportion of specialized physicians would seem to represent a problem for regions outside Lima, as there are relatively few physicians in these regions and generalists are able to handle a broader range of cases. However, it may be that private physicians in these settings fill a gap in health services by providing direct access to specialty care when public channels are cumbersome and equally costly when total number of health center visits and total time investment are considered.

\section{Regional issues}

According to the Ministry of Health, a total of 24780 practicing physicians, or 10 physicians per 10000 inhabitants, were living in Peru as of 1996 (22). We analyzed physician distribution by region and found a much higher ratio of physicians per 10000 inhabitants in coastal cities (13.7) compared to Andean (8.5) and jungle cities (6.7). This is not surprising, and reflects the unequal geographical distribution of medical human resources in Peru. In 1997, 60\% of all physicians in

\footnotetext{
2 Colegio Médico del Perú, personal communication, October 2004.
} 
Peru and $75.7 \%$ of those with a specialization were located in Lima alone, which is a coastal city (21). By comparison, approximately one-third of the general population lives in Lima. The number of physicians per 10000 inhabitants varies widely in other Latin American countries, ranging from 60.4 in Cuba and 20.6 in Brazil to 7.6 in Bolivia and 5.6 in Paraguay (23).

We also found that most private physicians in provinces outside Lima received their medical training in the provinces (37.5\% in Lima, $47.3 \%$ in other cities, and $15.2 \%$ abroad). This was particularly true of private physicians in the coastal and Andean regions. By comparison, those practicing in jungle cities were much more likely to have trained in Lima or abroad, suggesting that physicians who practice in these areas are either from other regions, or had to seek training in areas outside the jungle. If the latter is true, efforts to strengthen and develop existing medical schools in jungle areas would encourage local training of physicians and thereby help increase the physician workforce in this region.

\section{Gender issues}

We found that male physicians outnumbered female physicians in the population surveyed. It is important to note, however, that the proportion of female physicians in Peru has increased considerably since the 1960s, with women representing $4.7 \%$ of all physicians in 1964 but $18.5 \%$ in 1997 $(24,20)$. This phenomenon probably reflects the increasing social acceptance of women entering the professional workforce. In our study $22.9 \%$ of the private physicians surveyed were women, consistent with the national trend.

The main discrepancy found between the characteristics of male and female physicians is that male physicians were much more likely to be specialized, a phenomenon that may contribute to the gender discrepancy in the median fee per consultation. Of interest, in 1989 Alarcón et al. found that rates of specialization among male and female physicians were slightly but not significantly different $(69.7 \%$ among men, $58.8 \%$ among women, $P>$ 0.05) (25). Their number for the proportion of male specialists is similar to the proportion found in our study $(63.2 \%)$, but their figure for the proportion of female specialists differs greatly from our finding $(39.7 \%)$. This may indicate a particularly low tendency towards specialization among female physicians in the provinces, or that women with a medical specialty tend to practice in Lima.

In addition, private female physicians were more likely to treat female patients with STIs, although the overall number of consultations was similar for both sexes. Female patients may be more comfortable seeing female physicians for STIs, or female physicians may be more likely to practice where female STI cases are encountered. Another possible explanation is that female physicians may be more likely than male physicians to recognize and diagnose STIs in female patients. Our findings suggest that promoting medical training and practice for female physicians in the provinces outside Lima may benefit health care delivery because female physicians may be uniquely positioned to address public health problems in certain populations.

\section{Sexually transmitted infections and private physicians}

In this study most private physicians regardless of specialty reported managing STI cases (97.4\%). Patients may choose to see private physicians rather than a public practitioner for reasons of confidentiality, convenience, shorter waiting times, or better service (perceived or actual), among other reasons $(26,27)$. Although patients may believe that better care is provided in private settings, the opposite may be true in the case of STIs, given that private physicians for the most part do not receive regular training, whereas in the public sector there are multiple efforts to train health personnel. For example, public sector physicians in Peru have received train- ing in STI management several times in recent years, whereas similar efforts have not been directed specifically towards private physicians. A study in 2005 that examined patterns of STI management by private physicians in Peru found that treatment strategies for pelvic inflammatory disease and trichomoniasis were grossly inadequate, suggesting the need to train private physicians better in STI management (15). Studies from other parts of the world have shown similar findings $(28,29)$, and it is possible that the same pattern exists in the rest of Latin America, making research on the private sector and the impact of targeted training in STI management for private providers potentially worthwhile.

Our analysis also identified the most common STIs seen by private physicians in the 10 cities we surveyed. Most STI reports were etiologic in nature, although $24 \%$ of the conditions reported were syndromic. It should be kept in mind that the data on STIs reflect physician-reported cases, and not laboratory-diagnosed cases.

Our data add a valuable dimension to the existing literature on Peruvian physicians by examining private physicians as a subpopulation of medical doctors. Little direct information exists about this group in Peru, yet private practitioners represent an important part of the medical workforce. One barrier to the generalizability of our results is the exclusion of Lima from the study. Because about onethird of the population of Peru resides in Lima, it is difficult to evaluate numbers at a national level without data from the capital city. In addition, although the 10 cities in our study represented all regions of Peru, the study was nonetheless limited to larger cities with populations of 50000 or greater, and did not include data from rural areas. However, by excluding Lima from this study, we avoided confounding since the needs and resources of a city with almost 8 million inhabitants are very different from those of the smaller cities included in our survey, and we are therefore able to provide a clearer picture of health care resources and physician training 
in the provinces. Our data also enabled us to perform analyses based on gender and region that yielded interesting comparisons not found in prior studies. Finally, we were able to gather information about the proportion of private physicians who manage STIs, highlighting the fact that private physicians play an important role in managing STIs regardless of specialty, and that proper training of this group in STI management is important to ensure quality of care. Future studies would benefit from a greater emphasis on factors such as income, nationality, and exposure to and participation in government-sponsored training programs.

The importance of demographic profiling of the physician workforce in a developing country cannot be overemphasized. These data are critical to understanding trends and guiding policy decisions that influence medical education, physician distribution and community health. Such information is valuable on a regional level, providing frameworks for understanding patterns in physician workforce distribution, as well as information on the changing demographic and health care needs of the population. As shown by previous studies of private and public sector health care services in developing countries, a large proportion of patients with conditions of public health significance, including sexually transmitted infections, seek care in the largely unregulated "forprofit" private sector. Because the factors that influence private provider decisions may be different from those of public providers, and because the overlap between private and public sectors is complex, it is imperative that governments consider the role of private practitioners when developing, implementing, and evaluating strategies and policies to improve the quality of service provision. (30-32).
Acknowledgments. This research was supported by the Wellcome Trust (059131/Z/99/Z), the National Institutes of Health/NIAID STD Cooperative Research Center (NIAID AI31448), and the Center for AIDS Research (P30-AI27757). We would like to acknowledge the following institutions for their contribution to the background research of this study: the Peruvian College of Physicians, the Peruvian Ministry of Health, and the Pan American Health Organization-Lima Office. Special thanks as well to the national and local PREVEN coordinators: Julio Hilbert Gómez Paredes, María Isabel Valderrama Calderón, Lita Yohana Alvarado Herrera, Elvira Morales Ayala, Tutty Gamboa Sicha, Anamelba Perceros Mendoza, Miguel Huarcaya Fernandez, Alicia Villanueva Tovar, Carlos Alfonso Ortiz Goicochea, Yliana Solis Panduro, Ruth Yvone Carrión Castillo, and Digna Zambrano Ladines.

\section{REFERENCES}

1. Dimassi HI, Khaliq AA. Changing profile of Oklahoma physicians since 1928. J Okla State Med Assoc. 2004;97(2):57-63.

2. Sanmartin CA, Snidal L. Profile of Canadian physicians: results of the 1990 Physician Resource questionnaire. CMAJ. 1993;149(7): 977-84.

3. Troselj M, Mayer V, Kuzman M, Tomic B. [Demographic and educational characteristics of physicians in the in Croatia: overview]. [Abstract] Lijec Vjesn 2002;124(11-12):341-6.

4. Rosenbach ML, Harrow B, Cromwell J. A profile of emergency physicians 1984-1985: demographic characteristics, practice patterns, and income. Ann Emerg Med. 1986;15(11): 1261-7.

5. Kahn NB Jr, Schmittling G, Ostergaard D, Graham R. Specialty practice of family practice residency graduates, 1969 through 1993. A national study. JAMA. 1996;275(9):713-5.

6. Frank E, Rothenberg R, Brown WV, Maibach $\mathrm{H}$. Basic demographic and professional characteristic of US women physicians. West J Med. 1997;166(3):179-84.

7. Willke RJ. Practice mobility among young physicians. Med Care. 1991;19(10):977-88.

8. Kindig DA, Schmelzer JR, Hong W. Age distribution and turnover of physicians in nonmetropolitan counties of the United States. Health Serv Res. 1993;28(3):384.

9. Hayes-Bautista DE, Hsu P, Hayes-Bautista M, Stein RM, Dowling P, Beltran R, et al. Latino physician supply in California: sources, loca- tions, and projections. Acad Med. 2000;75(7): 727-36.

10. Chie WC, Chang SH, Yang HF. Factors affecting specialty and location of practice of government-sponsored physicians in Taiwan. [Abstract] J Formos Med Assoc. 1997;96(7): $535-41$.

11. Freshnock LJ, Goodman LJ. The organization of physician services in solo and group medical practice. Med Care. 1980;18(1):17-29.

12. Moore FD, Priebe C. Board-certified physicians in the United States, 1971-1986. N Engl J Med. 1991;324(8):536-43.

13. Hanson K, Berman P. Private health care provision in developing countries: a preliminary analysis of levels and composition. Health Policy and Planning. 1998;13(3):195-211.

14. Ayres Sicheri M, Chirinos O, Vera JC. El sector no público y la atención médica en el Perú. Proyecto Análisis del Sector Salud (ANSSAPerú). Informe Exploratorio $N^{\circ}$ 7. Lima, Peru: Organización Panamericana de la Salud; 1986.

15. Garcia PJ, Holmes KK. STI trends and patterns of treatment for STI by physicians in private practice in Peru. Sex Transm Infect. 2003; 79:403-7.

16. Chatterjee N, Leonard L, Ross M. The role of private physicians in STD control in two inner-city communities in Houston, Texas. J Public Health Manag Pract. 1999;5(5)34-9.

17. Benjarattanaporn $P$, Lindan $C P$, Mills $S$, Barclay J, Bennett A, Mugrditchian D, et al. Men with sexually transmitted diseases in Bangkok: where do they go for treatment and why? AIDS. 1997;11(Suppl 1):S87-95.

18. Garcia PJ, Gotuzzo E, Hughes JP, Holmes KK. Syndromic management of STIs in pharmacies: evaluation and randomized intervention trial. Sex Transm Inf 1998;74(Suppl 1): S153-8.

19. Organización Panamericana de la Salud. Análisis de la situación Perú, Programa Especial de Análisis de Salud. Lima, Peru: PAHO/ WHO; 2002.

20. Swayne Ossa J. Fuerza de Trabajo (Documento de trabajo). Dirección General de Desarrollo de Recursos Humanos. Lima, Peru: Escuela Nacional de Salud Pública. Ministerio de Salud; 1996

21. Bustíos Romaní, Carlos; Swayne Ossa Julio. Situación de la fuerza de trabajo médica en el Perú. Lima, Peru: Escuela Nacional de Salud Pública; 1998.

22. Peru, Ministerio de Salud. Censo de Infraestructura Sanitaria y Recursos del Sector Salud. Lima, Peru: MINSA, Oficina de Estadística e Informática; 1996.

23. Pan American Health Organization. Health Analysis and Information Systems Area. Regional Core Health Data Initiative; Technical Health Information System. Washington, DC: PAHO; 2004.

24. Hall T. Recursos Humanos de Salud. Lima, Perú; Ministerio de Salud Pública y Asistencia Social. Oficina Sectorial de Planificación de Salud; 1967. 
25. Alarcón J. Colegio Médico del Perú, Universidad Nacional Mayor de San Marcos, Instituto de Medicina Tropical Daniel A Carrión. Situación de trabajo y características socioeconómicas del Médico de Lima Metropolitana (resultados de una encuesta). Lima, Peru: Colegio Médico del Perú; 1989.

26. Nuwaha F. Determinants of choosing public or private health care among patients with sexually transmitted infections in Uganda. Sex Transm Dis. 2006;33(7):422-7.

27. Choi KH, Zheng X, Zhou H, Chen W, Mandel J. Treatment delay and reliance on private physicians among patients with sexually transmitted diseases in China. Int J STD AIDS. 1999;10(5):309-15.

28. Connolly AM, Wilkinson D, Harrison A, Lurie M, Karim SS. Inadequate treatment for sexually transmitted diseases in the South African private health sector. Int J STD AIDS. 1999;10(5):324-7.

29. Green M, Hoffman IF, Brathwaite A, Wedderburn M, Figueroa P, Behets F, et al. Improving sexually transmitted disease management in the private sector: the Jamaica experience. AIDS. 1998;12(Suppl 2):S67-72.

30. Brugha R, Zwi A. Improving the quality of private sector delivery of public health ser- vices: challenges and strategies. Health Policy Plan. 1998;13(2):107-20.

31. Berman P. Getting more from private health care in poor countries: a missed opportunity. International J Qual Health Care. 2001;13(4): 279-80.

32. Travis P, Cassels A. Safe in their hands? Engaging private providers in the quest for public health goals. Bull World Health Organ. 2006;84(6):427-7.

Manuscript received on 21 October 2005. Revised version accepted for publication on 11 September 2006.

RESUMEN Objetivos. Analizar las características demográficas y profesionales de los médicos privados en 10 ciudades de Perú y esclarecer el papel que desempeña la medicina privada en la atención de pacientes con infecciones de transmisión sexual (ITS).

Las infecciones de transmisión sexual y los médicos privados en Perú, 2003

Métodos. Como parte de un ensayo de intervención diseñado para mejorar el control de las ITS en 10 ciudades de Perú, se recopiló información detallada sobre el número de médicos de cada ciudad y se realizó una encuesta de puerta en puerta en todas las instituciones y consultorios, tanto privados como públicos. A todos los médicos contactados que tenían consulta privada se les pidió responder un cuestionario que recogía información demográfica y sobre la formación médica, especialidad, tipo de servicios privados y públicos que prestaba en ese momento, número de casos de ITS que atendía mensualmente y sus ingresos promedio por consulta.

Resultados. De los 2060 médicos que trabajaban en las 10 ciudades estudiadas, 507 informaron tener consulta privada, ya sea de forma exclusiva o compartida con otros trabajos clínicos. Casi todos los médicos privados $(97,4 \%)$ informaron que atendían casos de ITS. Se encontraron diferencias entre las regiones en cuanto a la densidad y el lugar de entrenamiento de los médicos privados. Además, se observaron variaciones significativas según el sexo en la proporción de médicos especialistas, los ingresos por consulta y el número de mujeres con ITS que atienden mensualmente.

Conclusiones. Los estudios sobre la disponibilidad de médicos pueden ofrecer una perspectiva interesante y de gran utilidad para abordar problemas de salud pública. Este estudio brinda una valiosa información que puede contribuir a comprender el importante papel que desempeñan los médicos privados en el control de las ITS en Perú.

Palavras clave Recursos humanos en salud, Perú, médicos, práctica privada, infecciones de transmisión sexual. 